\title{
Avaliação da degradação das terras nas regiões oeste e norte da cidade de Campina Grande, PB: um estudo de caso
}

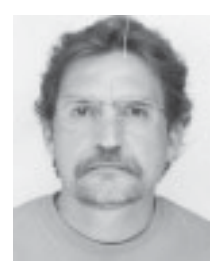

João M. de Moraes Neto ${ }^{1}$ Marx P. Barbosa ${ }^{2}$, Maria de F. Fernandes ${ }^{3}$ \& Miguel J. da Silva ${ }^{4}$

1 DEAg/CCT/UFPB. Av. Aprígio Veloso, 882, Bodocongó, CEP 58109-970, Campina Grande, PB. E-mail: moraes@Imrs.pb.gov.br (Foto)

2 DEAg/CCT/UFPB. E-mail: marx@Imrs.pb.gov.br

3 DEAg/CCT/UFPB. E-mail: fatima@Imrs.pb.gov.br

4 DEAg/CCT/UFPB

Protocolo $104-30 / 8 / 2000$

\begin{abstract}
Resumo: Objetivou-se, com o presente trabalho, avaliar a degradação das terras nas regiões oeste e norte da cidade de Campina Grande, PB, cuja metodologia incluiu: processamento digital de imagem, interpretação visual e correlação com os dados de campo. Na análise digital utilizou-se o método de classificação supervisionada por Maximoverossimilhança (Maxver), cujos resultados se mostraram satisfatórios permitindo, assim, o mapeamento das principais áreas degradadas da região de estudo.
\end{abstract}

Palavras-chave: imagem orbital, processamento digital, classificação supervisionada

\section{Evaluation of land degradation in north and western regions of Campina Grande, PB: A case study}

\begin{abstract}
The objective of the present work was to evaluate and characterize the land degradation in western and northern regions of Campina Grande, PB. Data were obtained through digital image processing, followed by visual interpretation of the digitally processed image and final field checking. The Gaussian Maximum Likelihood Classifier was used in digital analysis. The results of the classification showed to be satisfactory, allowing to map the main degraded areas of the studied region.
\end{abstract}

Key words: image orbital, digital processing, supervised classification

\section{INTRODUÇÃO}

Situada na Microrregião Homogênea Agreste da Borborema, Campina Grande ocupa uma área de aproximadamente 644,1 $\mathrm{km}^{2}$, representando o segundo maior centro urbano do Estado, constituindo-se em um centro de polarização de maior importância econômica da Mesorregião. Sua geologia é representada por terrenos do Pré-Cambriano e, de acordo com a classificação de Köppen, o clima predominante é do tipo As' - quente e úmido com chuvas de outono-inverno. A precipitação pluviométrica está em torno de $700 \mathrm{~mm}$ anuais. A temperatura média anual é de $26^{\circ} \mathrm{C}$, com média das mínimas inferior a $22^{\circ} \mathrm{C}$. A umidade relativa do ar é em torno de $80 \%$. A vegetação é composta pela floresta caducifólia, que transiciona para caatinga hipoxerófila. Os solos predominantes na área são: Solonetz Solodizado, Regossolo Eutrófico, Vertissolos e Solos Litólicos Eutróficos (Brasil, 1972). Segundo Rocha (1997) uma área deteriorada pode recuperar-se, se mantida em repouso, desde que essa deterioração não ultrapasse $10 \%$ e quando isso ocorre, é necessário a intervenção humana.

A deterioração do solo ocasionada pela erosão antrópica (Rocha, 1999) resultante da influência das atividades do homem, está ligada à falta de cobertura vegetal, fazendo com que a precipitação pluviométrica faça o arraste das camadas do solo. Levando-se em consideração a dinâmica da ocupação das áreas urbanas e a velocidade de degradação das terras nas regiões oeste e norte de Campina Grande, a utilização de imagens de satélite, complementada com o trabalho de campo, é de fundamental importância no monitoramento do meio ambiente, para se avaliar o grau e a intensidade da degradação das terras. $\mathrm{O}$ município de Campina Grande carece de informações sobre a forma de organização do seu espaço geográfico e ocupação do solo, principalmente nas áreas periféricas, onde ocorre de forma desordenada.

O levantamento da cobertura vegetal e do uso da terra é indispensável para o planejamento racional que irá superar problemas de desenvolvimento descontrolado e de deterioração da qualidade ambiental, porém as técnicas convencionais caracterizam-se pelo alto custo e pela dificuldade de se obter dados em um curto período (Pereira et al., 1989). Considerando-se a dinâmica de ocupação, a utilização de imagens de satélite tornou possível o acompanhamento periódico da cobertura vegetal e uso da terra, para avaliação de seu desenvolvimento (Andrade et al., 1998). 


\section{MATERIAL E MÉTODOS}

Utilizou-se imagem TM/LANDSAT-5 no formato digital, referente à órbita 214 , ponto 065 , quadrante $\mathrm{W}$ e dados cartográficos e bibliográficos, além do Sistema de Tratamento de Imagens (SITIM-340, versão 2.5E, desenvolvido pelo INPE). No tratamento digital, a imagem foi ampliada para a escala de 1:40.000. Utilizou-se o realce de contraste linear e a transformação RGB das bandas 5, 4 e 3. O método de classificação supervisionada, utilizado foi o da Maximoverossimilhança (Maxver) em que a identificação do objeto é feita pelas características pontuais (por amostragem). Este classificador avalia tanto a variância como a covariância dos padrões de resposta espectral de uma categoria, quando está classificando um pixel desconhecido (Barbosa, 1998). O algoritmo estatístico de classificação "Maxver", consiste em classificar a imagem ponto a ponto, usando-se o critério de maximoverossimilhança, a partir de classes fornecidas pelo usuário (Menezes, 1991). As funções de densidade de probabilidade são usadas para se classificar pixels desconhecidos, computando-se a probabilidade de seu valor pertencer a cada uma das categorias ou classes definidas. O trabalho de campo foi realizado através de um percurso em toda a área, onde foram observados os diversos fatores atuantes na degradação das terras.

\section{RESULTADOS E DISCUSSÃO}

A transformação RGB das bandas 5, 4 e 3 (Figura 1A), possibilitou a análise dos elementos solo, vegetação, área urbana, sombra, etc. O resultado da classificação pelo método Maxver, em que a identificação do objeto é feita pelas características pontuais, é apresentado na Figura 1B, e pode ser considerado satisfatório,

A.

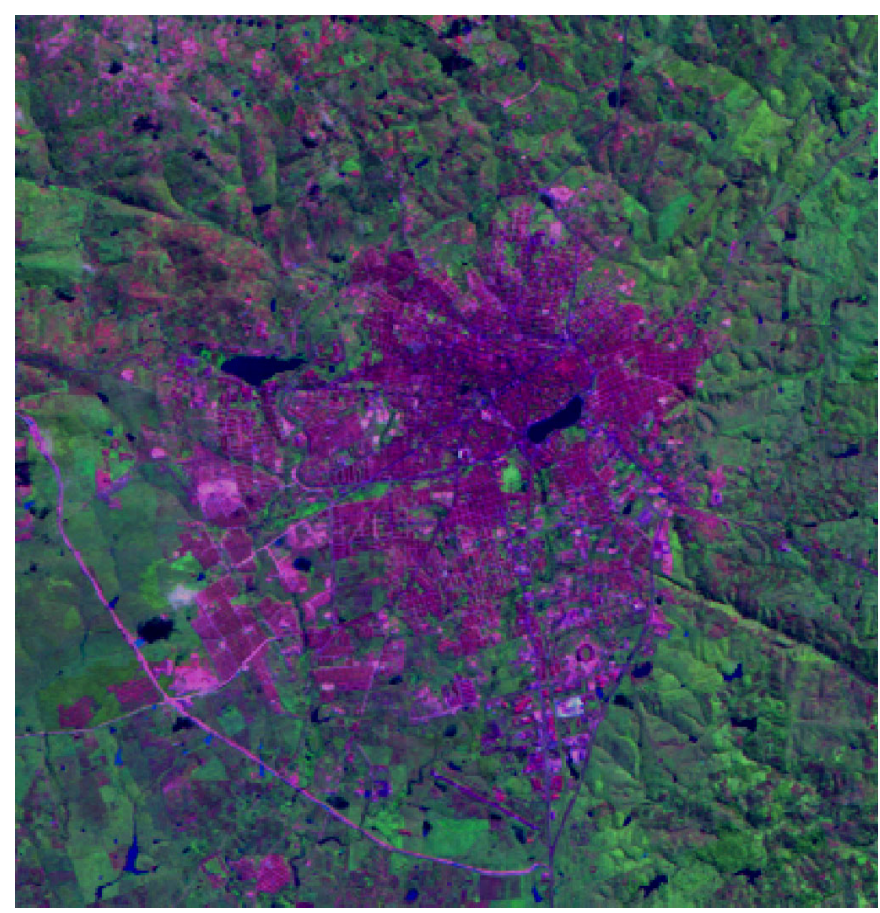

embora tenha apresentado pequena confusão entre a alça sudoeste (parte do contorno viário da cidade, em fase de conclusão) com a área urbana. Os corpos d'água, facilmente identificados pela textura muito fina e formas geométricas características, apresentaram diferentes tonalidades de azul, relacionadas com a quantidade de material em suspensão em cada um deles.

As áreas de solo exposto, sem atividade agrícola apresentaram, em muitos casos, o substrato rochoso muito próximo à superfície, ou até mesmo aflorante, identificados pela cor rosa, a oeste e norte da cidade. As visitas de campo permitiram constatar-se que essas áreas estão seriamente comprometidas e em estado bastante avançado de degradação, em função da intensa ação antrópica, aumentando a vulnerabilidade das áreas vizinhas, em que se observa a erosão dos solos, tanto na forma laminar como por sulcos e, em alguns pontos, já evoluindo para voçorocas, conforme foi observado durante os trabalhos de reconhecimento de campo . A prática inadequada da agricultura, pelo chamado plantio "morro abaixo", tem contribuído bastante para a degradação das encostas. A vegetação natural mais densa encontra-se presente nas áreas mais elevadas e está representada por espécies arbóreos e arbóreo-arbustivos.

Nas demais áreas, observa-se variação na densidade da vegetação e, em alguns lugares, onde a atividade agrícola foi abandonada, há uma regeneração da mesma, principalmente por espécies invasoras. Onde a vegetação é mais rala, a atividade é predominantemente pastoril observando-se, em alguns pontos sua rarefação, caracterizando a alta vulnerabilidade dos solos a erosão. A expansão da periferia está ocorrendo de forma bastante desordenada, aumentando os riscos e vulnerabilidade da qualidade de vida de seus habitantes.

B.

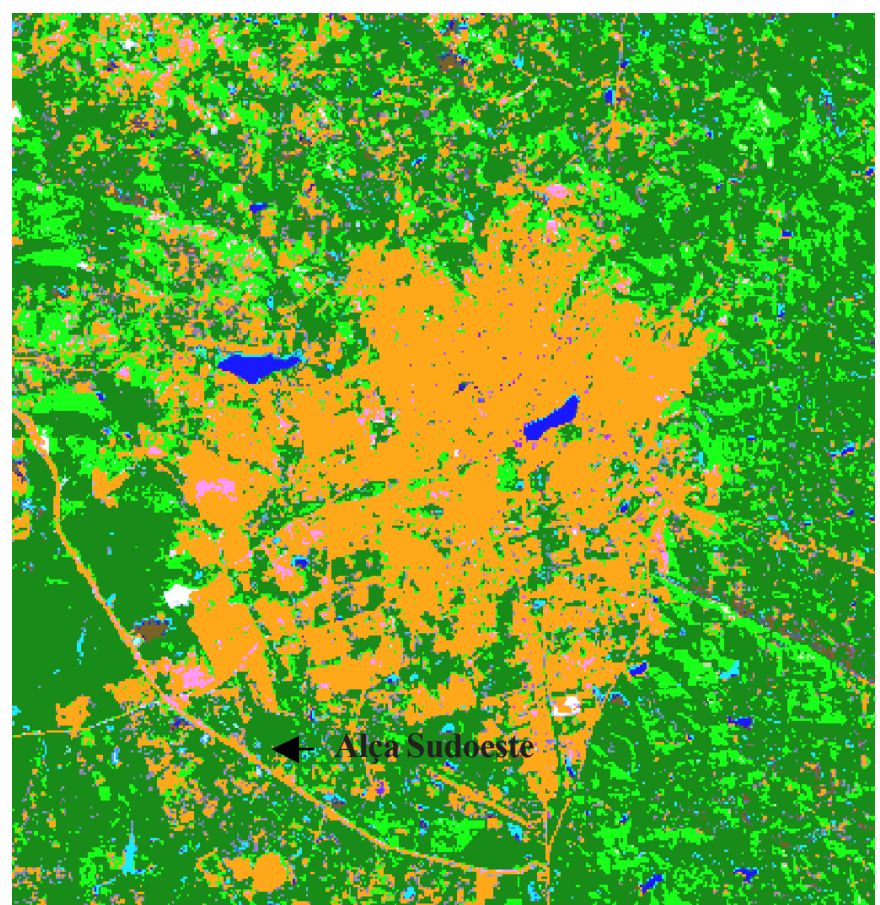

Vegetação densa

$\square$ Área urbana

Vegetação rala

Solo exposto

Água com pouco material em suspensão
Água com material em suspensão

Figura 1. Transformação RGB - bandas 5, 4 e 3 (A) e imagem classificada pelo Maxver (B) 


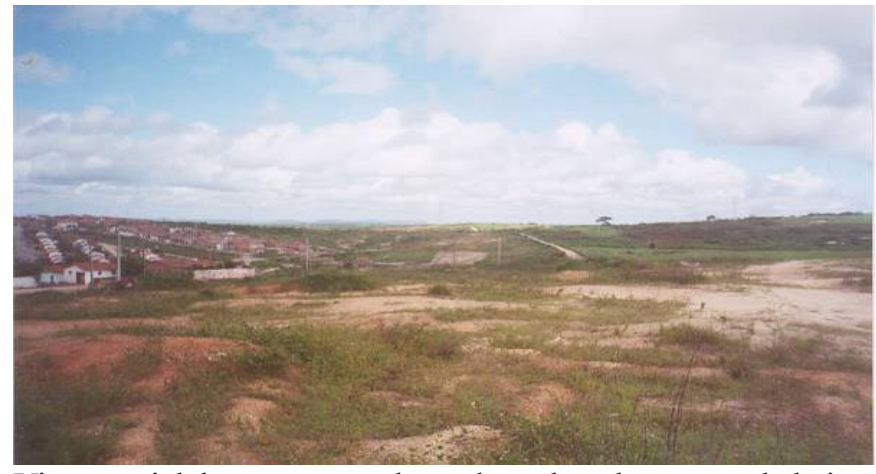

Vista parcial da ocupação urbana desordenada, a oeste do bairro das Malvinas

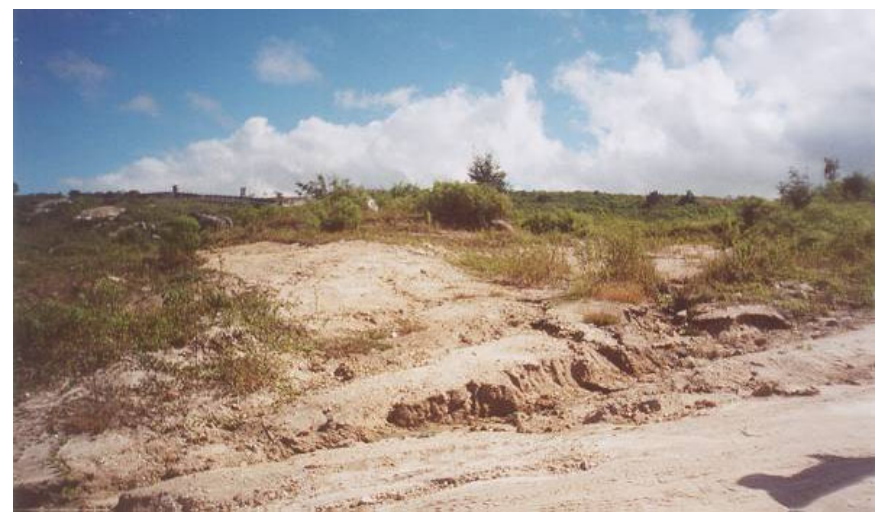

Áreas degradadas com formação de sulcos evoluindo para voçorocas

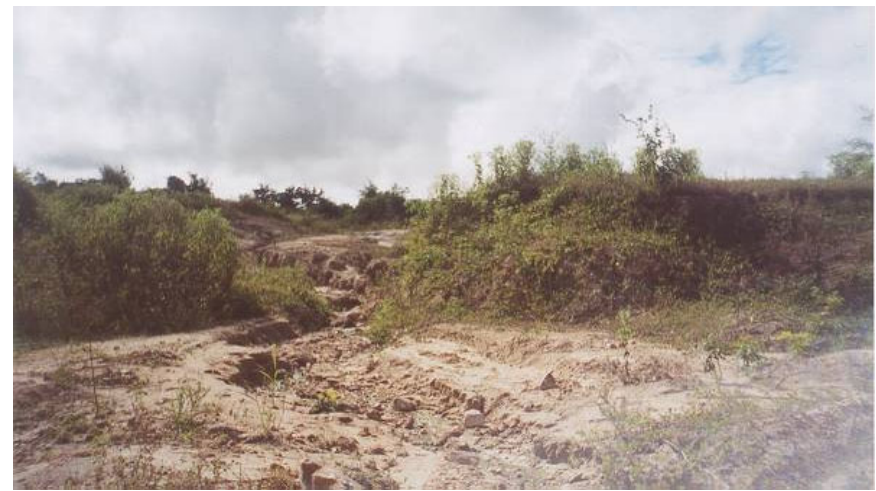

Área em processo de formação de voçorocas

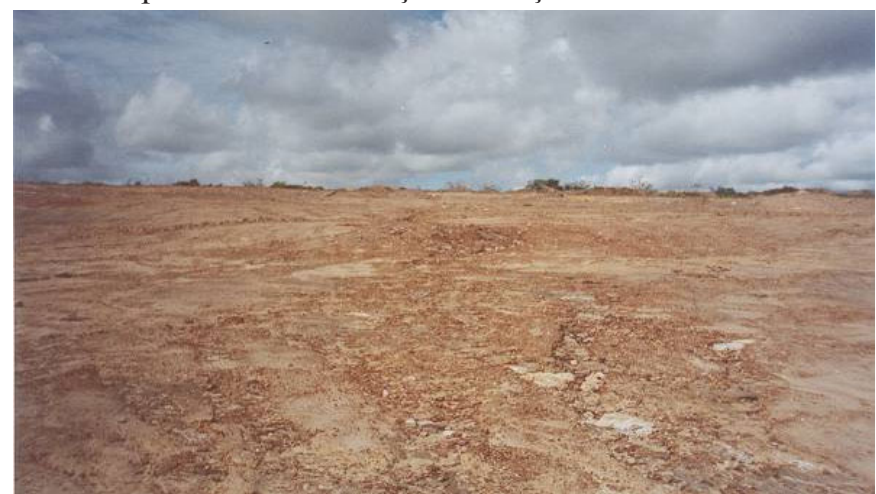

Área com alto índice de degradação

Figura 2. Vista parcial da área de estudo, com observações para a intensidade da degradação na região de Campina Grande, PB

Ressalta-se ainda que, praticamente, não existe controle nem fiscalização ambiental por parte das autoridades competentes, bem como, a aplicação de práticas conservacionistas que tornem essas áreas menos vulneráveis aos processos de degradação. Um planejamento mais criterioso do uso desses solos é recomendável, já que a retirada de material para construção civil implica em sérios níveis de degradação do meio ambiente, colocando em risco os recursos naturais disponíveis.

A Figura 2, mostra a intensidade da degradação nas regiões oeste e norte da cidade de Campina Grande, além do crescimento desordenado de sua área urbana.

\section{CONCLUSÕES}

1. Os estudos indicam que essas áreas se encontram seriamente comprometidas, em estado bastante avançado de degradação, em função da intensa ação antrópica aliada à grande retirada de material para construção civil, realizada de forma indiscriminada aumentando, assim, a vulnerabilidade dessas áreas que, em alguns pontos, e se não forem efetuadas práticas de conservação e contenção da retirada do material, dificilmente serão recuperadas.

2. Verifica-se, ainda, que a área situada nas proximidades do Riacho Bodocongó, onde a prática inadequada do uso dos solos, pelo chamado plantio "morro abaixo", tem contribuído bastante para a degradação das encostas.

3. Verifica-se que a ocupação urbana desordenada, principalmente nas proximidades do conjunto das Malvinas, onde também foram observados problemas de lixo lançado em terrenos baldios e a inexistência de saneamento básico, favorece o aumento da degradação ambiental, que já se apresenta de forma bem acentuada.

\section{LITERATURA CITADA}

Andrade, N.S. de O.; Araújo, L.S.; Numata, I. Estudo da dinâmica da cobertura vegetal e uso da terra na região de JI-Paraná/RO. INPE. 1998. 10p.

Barbosa, M.P. Sensoriamento Remoto. Processamento digital de imagens. Programa de suporte técnico à gestão de recursos hídricos-ABEAS. Curso de Especialização em Sensoriamento Remoto e SIG. Brasília, 1998, 23p. Módulo 6-B

Brasil. Ministério da Agricultura. I - Levantamento Exploratório, Reconhecimento de Solos do Estado da Paraíba. II Interpretação para uso agrícola dos solos do Estado da Paraíba. Rio de Janeiro: M.A/CONTAP/USAID/BRASIL. 1972. 683p. Boletim DPFS, EPE-MA, 15 - Pedologia, 8

Menezes, P.R.; Assad, E.D.; Sano, E.E. Introdução ao processamento digital de imagens digitais de satélites de sensoriamento remoto. Ed. Brasília: Universitária de Brasília. 1991,96p.

Pereira, N.; Kurkdjdjian, M.L.N.; Foresti, C. Cobertura e uso da terra através de sensoriamento remoto. São José dos Campos: INPE. 1989. 118p. INPE-5032-MD/042

Rocha, J.S.M. da. Manual de projetos ambientais. Santa Maria: Imprensa Universitária. 1997. 423p.

Rocha, J.S.M. da. Educação ambiental, ensino fundamental médio e superior. 2 ed. Santa Maria: Imprensa Universitária, 1999.548p. 